Revista Verde de Agroecologia e Desenvolvimento Sustentável

http://www.gvaa.com.br/revista/index.php/RVADS

ARTIGO CIENTÍFICO

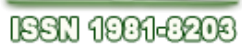

DOI: http://dx.doi.org/10.18378/rvads.v10i1.2809

\title{
Diagnóstico e desenvolvimento inicial de mamoneira em solos de áreas degradadas
}

\section{Diagnosis and initial development of mamoneira in soils of degraded areas}

\author{
Rivaldo Vital dos Santos ${ }^{1}$, Girlânio Holanda da Silva ${ }^{2}$, Kely Dayane Silva do Ó$^{3}$, Adriana de F. Meira Vital ${ }^{4}$
}

\begin{abstract}
RESUMO - A degradação do solo no semiárido também ocorre pelo desmatamento da Caatinga e pela remoção da camada superficial do solo, cujo destino é a indústria de cerâmica ou olarias. O presente trabalho objetivou avaliar o crescimento da mamoneira em solos degradados. Os tratamentos consistiram de solos degradados: subsolo degradado-1, subsolo degradado-2 e área desmatada; quatro doses de fósforo $\left(0,100,200,300 \mathrm{mgkg}^{-1} \mathrm{P}\right)$, com três repetições. As testemunhas absolutas, sem fósforo, corresponderam ao solo salinizado não corrigido, solo-1 não degradado, solo-2 não degradado e solo de caatinga não desmatada. O solo degradado por sais, o subsolo-2, recebeu correção com gesso agrícola, foi incubado e lavado. Os resultados demonstraram que a análise do subsolo degradado revelou alta salinidade e baixos teores de fósforo e matéria orgânica, o subsolo degradado salino exige correção com gesso para tornar possível o cultivo da mamona em caatinga desmatada e subsolos degradados. As doses de fósforo não promoveram desenvolvimento significativo em mudas de mamona.
\end{abstract}

Palavras-chave: Ricinus communis; química do solo; produção de mudas.

ABSTRACT - The soil degradation in semiarid occurs also by the deforestation of Caatinga and the removal of topsoil, whose fate is the industry of ceramic or pottery. This study aimed to evaluate the growth of mamoneira in degraded soils. Treatments consisted of degraded soils: 1-degraded subsoil, subsoil-2 degraded and deforested area, four doses of phosphorus (0, 100, 200, $300 \mathrm{mg} \mathrm{kg}^{-1} \mathrm{P}$ ), with three replications. Absolute witnesses, without phosphorus corresponded to salinized soil uncorrected, non-degraded soil-1, 2-non-degraded soil and soil of the caatinga not deforested. The degraded soil by salts, subsoil-2, received correction with gypsum, was incubated and washed. The results showed that the analysis of degraded subsoil revealed high salinity and low phosphorus concentration and organic matter, degraded subsoil saline demands correction with gypsum to make the cultivation of mamona in deforested and degraded caatinga subsoils possible. The phosphorus levels did not promote significant development in seedlings of mamona

Keywords: Ricinus communis; soil chemistry; seedlings production.

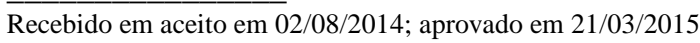

\footnotetext{
*Autor para correspondência.

${ }^{1}$ Professor do Centro de Saúde e Tecnologia Rural da Universidade Federal de Campina Grande, Campus de Patos - PB. e-mail: rvital@cstr.ufcg.edu.br.

2*Mestrando em Ciências Florestais pela Universidade Federal de Lavras - MG. e-mail: girlanio_holanda@hotmail.com.

${ }^{3}$ Mestranda em Ciências Florestais pela Universidade Federal de Campina Grande - PB, e-mail: kelydaiane_11@ @otmail.com.

${ }^{4}$ Profa. do Centro de Desenvolvimento Sustentável do Semiárido da Universidade Federal de Campina Grande. e-mail: vital.adriana@gmail.com.
} 


\section{INTRODUÇÃO}

$\mathrm{Na}$ Caatinga profundas interferências antrópicas resultam em severa degradação ambiental, com consequente redução na fertilidade dos solos, tornando-os pouco produtivos. Dentre as práticas que degradam o solo no semiárido, pode-se citar a remoção de horizontes superficiais e profundos do solo, cujo destino é a indústria de cerâmica ou olarias e o desmatamento da Caatinga. No primeiro caso, há retirada total ou parcialmente do horizonte mais fértil do solo para a confecção de telhas, tijolos, vasos e a construção civil, expondo os horizontes subsuperficiais, imprestáveis à agricultura.

Designadamente, a degradação do solo em áreas onde há exploração ocorre também a remoção da cobertura vegetal e das camadas de solo fértil superficial, o que causa grande impacto negativo na microbiota do solo, reduzindo o número de bactérias, fungos solubilizadores de fosfato e a atividade microbiana do solo (SCHIAVO, 2005). Nessas condições, a revegetação por processos naturais é extremamente limitada. Dessa forma, a intervenção antrópica se faz necessária, para a melhoria do ambiente químico, físico e biológico do solo, como também pela seleção e introdução de espécies adaptadas, capazes de restabelecer os processos de sucessão natural (CHAER et al. 2011).

Assim, é imprescindível identificar os atributos limitantes nesses solos, propor um manejo adequado visando a sua reintegração à produção agrícola, com o cultivo de espécies de expressão econômica.

Pertencente à família Euphorbiaceae, a mamona (Ricinus communis L.) engloba um vasto número de espécies nativas da região tropical, possui em seus subprodutos compostos químicos de grande interesse industrial, como o óleo extraído de suas sementes, que possui propriedades químicas especiais, podendo ser utilizado como ingrediente na fabricação de lubrificantes para aviões a jato, fluidos hidráulicos, no preparo de tintas, vernizes e plásticos (Oliveira et al., 2006).

Essa cultura tem-se comportado de forma resistente ao clima, em condições em que outras culturas poderiam sofrer perda na produtividade, de forma tal que sua utilização prévia pode melhorar os atributos químicos, físicos, físicoquímicos do solo, como também na recuperação de áreas degradadas (OLIVEIRA et al., 2006; AGUIAR et al, 2000; NASCIMENTO et al., 2003; ALVES \& SUZUKI, 2004).

Dessa forma, o presente trabalho objetivou-se diagnosticar os atributos do solo que caracterizam sua degradação, propor correção e avaliar o crescimento da mamona em diferentes solos degradados.

\section{MATERIAL E MÉTODOS}

\section{Localização da área experimental}

O experimento foi conduzido em casa de vegetação no Viveiro Florestal da Unidade Acadêmica de Engenharia Florestal (Centro de Saúde e Tecnologia Rural - Universidade Federal de Campina Grande, campus Patos - PB), cuja altitude é de $242 \mathrm{~m}$ com as seguintes coordenadas geográficas: latitude $7^{\circ} 1{ }^{\prime} 28^{\prime \prime} \mathrm{S}$, longitude $37^{\circ} 16^{\prime} 48^{\prime \prime} \mathrm{W}$ do Meridiano de Greenwich. Localizado na região semiárida do Estado da Paraíba.
O clima da região conforme a classificação de Köppen é do tipo BSh-semiárido quente e seco, com temperatura média anual de $28^{\circ} \mathrm{C}$ e umidade relativa do ar em torno de 55\%. Apresenta pluviosidade média anual de 675 $\mathrm{mm}$ com chuvas irregulares, concentrando-se nos meses de julho a fevereiro o período mais seco e de março a junho o mais chuvoso (BEZERRA, 2012).

\section{Coleta de solo e análises}

O solo utilizado no experimento foi coletado em duas áreas fazenda Pilões (Área 1) e fazenda Vapor (Área 2) na profundidade de 0-30 $\mathrm{cm}$, ambas situadas no município de Patos-PB, sendo caracterizados quanto aos atributos químicos e físicos. Na área 1 coletou-se: subsolo 1 não degradado (S1), subsolo degradado 1 (SD1), solo de caatinga não desmatada (AND) e desmatada (AD), enquanto que na área 2: solo 2 não degradado (S2) e subsolo degradado 2 (SD2) ambos salinos (Figura 1). Nas áreas foram identificados indicadores de degradação como: presença de sulco de erosão e decapeamento do solo, ou seja, a remoção da camada superficial.

As amostras de solo foram secos ao ar, destorroada, peneiradas com malha de $2 \mathrm{~mm}$, homogeneizadas e encaminhados para o Laboratório de Solos da Unidade Acadêmica de Engenharia Florestal (Centro de Saúde e Tecnologia Rural - Universidade Federal de Campina Grande, campus Patos - PB), para determinações de seus atributos químicos e físicos, conforme metodologia descrita pela Embrapa (1997).

\section{Tratamentos}

$\mathrm{O}$ experimento foi desenvolvido em um esquema fatorial $3 \times 4+4$, sendo em três tipos de solo (subsolo degradado 1, subsolo degradado 2 e solo de caatinga desmatada), com 4 doses de fósforo $(0,100,200,300)$ com 4 tratamentos adicionais: solo salinizado não corrigido, solo 1 não degradado, solo 2 não degradado e solo de caatinga não desmatada) sem doses de fósforo, com três repetições, totalizando 48 vasos com capacidade para 7 litros.

\section{Instalação e condução do experimento}

O subsolo degradado 2 recebeu incorporação prévia do corretivo gesso agrícola, na dosagem $20 \mathrm{gkg}^{-1}$, permaneceu incubado durante 15 dias na capacidade de campo, tendo em seguida recebido uma lâmina de água destilada correspondente a 2,5 vezes sua capacidade de campo (3,5 litros vaso $^{-1}$ ), enquanto que nas demais não se incorporou gesso. Para calcular a necessidade de gesso (NG), utilizou-se a fórmula $\mathrm{Y}=1,1 \mathrm{x}+0,54$, segundo CHAUHAN \& CHAUHAN (1979). A fonte de fósforo aplicada foi o superfosfato simples, previamente triturado.

As sementes de mamona utilizadas foram fornecidas pelo Instituto Nacional do Semiárido (INSA), no município de Campina Grande - PB. No semeio foram utilizadas quatro sementes por vaso. Oito dias após a germinação foi efetuado o desbaste, deixando-se uma muda por vaso, considerando a muda mais vigorosa e central, avaliando-se, assim, altura, diâmetro do caule e número de folhas semanalmente. A massa radicular e da parte aérea foram mensurados no término do experimento. 


\section{Variáveis analisadas}

Avaliaram-se a cada oito dias, mensurações do comprimento das plantas com régua graduada em centímetros, diâmetro do colo através de paquímetro digital e número de folhas. Em seguida o material vegetal da parte aérea e das raízes foram coletados e acondicionados em sacos de papel, secos em estufa com circulação forçada de ar a $65^{\circ} \mathrm{C}$ durante 48 horas. Após secagem determinou-se material vegetal seco da parte aérea e das raízes.

\section{Análises estatísticas}

As variáveis estudadas foram submetidas à análise de variância, análise de regressão polinomial para verificar o efeito das doses de fósforo e teste de Tukey para as diferentes áreas. Os testes foram realizados ao nível de 5\% de probabilidade, utilizando o programa estatístico SISVAR (FERREIRA, 2010).

\section{RESULTADOS E DISCUSSÃO}

\section{Diagnóstico dos atributos químicos dos solos}

A interpretação dos resultados dos atributos químicos discutidos a seguir baseiam-se nas referências: Recomendações de Adubação e Calagem para o Estado do Ceará (1993); Tomé Jr. (1997); Sugestões de adubação para o estado da Paraíba - $1^{\text {a }}$ aproximação (1979); (CFSEMG, 1999). Os resultados que constam na tabela 1 são discutidos a seguir.

Tabela 1. Atributos químicos dos solos das áreas estudadas.

\begin{tabular}{|c|c|c|c|c|c|c|c|c|c|c|c|c|c|}
\hline Solos & $\mathrm{pH}$ & $\begin{array}{c}\mathrm{MO} \\
\mathrm{g} \mathrm{dm}^{-3}\end{array}$ & $\begin{array}{c}\mathrm{P} \\
\mathrm{mg} \cdot \mathrm{dm}^{-3}\end{array}$ & $\mathrm{Ca}$ & $\mathrm{Mg}$ & $\begin{array}{c}\mathrm{K} \\
\mathrm{cmol}\end{array}$ & $\begin{array}{c}\mathrm{Na} \\
-3 \quad- \\
\end{array}$ & $\mathrm{H}+\mathrm{Al}$ & $\mathrm{T}$ & $\begin{array}{l}\mathrm{V} \\
\% \\
\end{array}$ & $\begin{array}{l}\mathrm{CE}_{1: 5} \\
\mathrm{dS} \mathrm{\textrm {m } ^ { - 1 }} \\
\end{array}$ & $\mathrm{CE}^{*}{ }_{\mathrm{ES}}$ & PST \\
\hline S1 & 5,5 & 11,5 & 9,2 & 9,0 & 2,2 & 0,32 & 0,33 & 1,9 & 13,8 & 86,2 & 0,07 & 0,6 & 2,4 \\
\hline S2 & 5,6 & 6,3 & 12,9 & 3,0 & 1,6 & 0,38 & 0,37 & 1,5 & 6,9 & 78,1 & 0,30 & 2,6 & 5,4 \\
\hline SD1 & 5,3 & 6,3 & 16,5 & 9,0 & 2,6 & 0,31 & 0,40 & 1,6 & 13,9 & 88,5 & 0,03 & 0,3 & 2,9 \\
\hline SD2 & 7,0 & 2,9 & 17,9 & 10,1 & 2,8 & 0,16 & 2,28 & 1,0 & 16,3 & 93,9 & 0,74 & 6,3 & 14,0 \\
\hline $\mathrm{AD}$ & 5,4 & 11,5 & 1,6 & 3,4 & 1,6 & 0,17 & 0,35 & 1,6 & 7,1 & 77,5 & 0,05 & 0,4 & 4,9 \\
\hline AND & 5,7 & 12,9 & 4,8 & 5,1 & 1,4 & 0,49 & 0,28 & 2,0 & 9,3 & 78,4 & 0,02 & 0,2 & 3,0 \\
\hline
\end{tabular}

* S1 = Camada superficial do subsolo não degradado. S2 = Camada superficial do subsolo não degradado salino. SD1 = Subsolo degradado não salino 1. SD2 $=$ Subsolo degradado salino $2 . \mathrm{AD}=$ Solo de caatinga desmatada. $\mathrm{AND}=$ Solo de caatinga não desmatada. $* * \mathrm{CEes}=\mathrm{Condutividade}$ elétrica do extrato de saturação estimado.

Os valores de $\mathrm{pH}$ nas áreas variaram de 5,3 a 7,0 indicando a presença de solos ácidos a neutros. Os valores de $\mathrm{pH}$ de 5,6 e 5,7 da camada superficial $(0-30 \mathrm{~cm})$ da área 2 e da área não desmatada, ou seja da caatinga nativa, não são preocupantes quanto a reação dos solos, não necessitando de correção pela calagem. Quanto aos valores de 5,3 e 5,4 há necessidade de monitoramento da reação do solo após o cultivo. Ainda relativo ao $\mathrm{pH} 7,0$, neutro e mais alto em relação aos demais, deve-se a presença de condições de sodicidade do solo expressada pelo maior percentual de sódio trocável (PST), igual a 14. Isto pode estar associado à maior concentração de ânions, tais como hidroxila $\left(\mathrm{OH}^{-}\right)$, carbonato $\left(\mathrm{CO}_{3}^{-2}\right)$ e bicarbonato $\left(\mathrm{HCO}_{3}^{-}\right)$.

Em todas as áreas avaliadas os teores de matéria orgânica do solo foram muito baixos, com valores variando de 2,9 a $12,9 \mathrm{gdm}^{-3}$. Os menores valores foram encontrados nos subsolos: 2,9 no subsolo da Fazenda Vapor e $6,3 \mathrm{gdm}^{-3}$ no subsolo do Sítio Pilões.

Os teores de fósforo dos solos nas áreas em estudo variaram de 1,6 a $17,9 \mathrm{mgdm}^{-3}$. Considerando que os teores médios são de 15 a $30 \mathrm{mgdm}^{-3}$, conclui-se que apenas os solos provenientes das camadas subsuperficiais apresentaram teores médios de fósforo, e as demais áreas valores baixos desse nutriente. Dessa forma, o manejo do solo nessas áreas requer, antes do cultivo de qualquer espécie, a aplicação de adubos fosfatados, além disso, como os solos apresentam reação levemente ácida, inclusive apresentando área de reação neutra $(\mathrm{pH}=7,0)$ e os teores de cálcio e magnésio são altos, não há necessidade de calagem.

Quanto aos teores de $\mathrm{Ca}$ apenas os solos das áreas desmatadas e da camada superficial do solo da fazenda Vapor apresentaram teores médios: 3,4 e 3,0, cmol $_{\mathrm{c}} \mathrm{dm}^{-3}$, respectivamente. As amostras coletadas no subsolo da
Fazenda Vapor, no subsolo do Sítio Pilões, na camada superficial do Sítio Pilões e na área desmatada foram altas, com valores de 10,$0 ; \quad 9,0 ; \quad 9,0$ e $5,1 \quad$ cmol $_{c} \mathrm{dm}^{-3}$, respectivamente. Já os teores de magnésio variaram de 1,4 a $2,8 \mathrm{cmol}_{\mathrm{c}} \mathrm{dm}^{-3}$ nas áreas desmatada e na do subsolo da Fazenda Vapor, respectivamente. Tomando como referência os teores médios de 0,8 a $1,6 \mathrm{cmol}_{\mathrm{c}} \mathrm{dm}^{-3}$, as áreas da camada superficial (S1) e do subsolo (SD1) e o subsolo da Fazenda Vapor (SD2) apresentaram teores altos de $\mathrm{Mg}, 2,2 ; 2,6$ e 2,8 $\mathrm{cmol}_{\mathrm{C}} \mathrm{dm}^{-3}$, respectivamente.

Assim, quando cultivadas, não há necessidade de uma aplicação inicial de calcário dolomítico. Relativo ao potássio no solo apenas as áreas subsolo 2 (SD2) e área desmatada (AD) exibiram teores médios $(0,16$ e 0,17 $\mathrm{cmol}_{\mathrm{c}} \mathrm{dm}^{-3}$, respectivamente), nas demais áreas a análise revelou de valores altos $\left(0,32 \mathrm{cmol}_{\mathrm{c}} \mathrm{dm}^{-3}\right)$ a muito altos $(0,49$ $\mathrm{cmol}_{\mathrm{c}} \mathrm{dm}^{-3}$ ) de potássio no solo. Os valores $\mathrm{de} \mathrm{H}+\mathrm{Al}$ foram baixos nos solos de todas as áreas, o que é uma característica dos solos do semiárido, fato associado a baixa acidez e a presença de teores altos de $\mathrm{Ca}$ e $\mathrm{Mg}$.

Os teores de sódio foram baixos em todas as áreas, exceto para o subsolo 2 (SD2), com valor de $2,28 \mathrm{cmol}_{\mathrm{C}} \mathrm{dm}^{-3}$, o que resulta numa percentagem de sódio trocável alta (PST = 14). No entanto, as outras áreas carecem de um constante monitoramento relativo aos teores de sódio, principalmente na área da Fazenda Vapor. Tal fato encontra-se associado à condutividade elétrica da solução do solo, que expressou valores preocupantes, ou seja, 6,3 e 2,6 $\mathrm{dS} \mathrm{m} \mathrm{m}^{-1}$ para o subsolo e camada superficial da Fazenda Vapor, respectivamente.

A análise dos valores da saturação por bases sugerem solos de elevada fertilidade química, no entanto, os solos dessas áreas têm limitações no que se refere aos teores de 
matéria orgânica, fósforo "disponível” e teores de sais solúveis e sódio trocável.

\section{Atributos Físicos}

Relativo às análises granulométricas, o solo revelou texturas franco arenosa, franco argilo arenosa e areia franca, com predominância da primeira.

A predominância de granulometria de solos de textura franco arenosa indica que os solos têm adequada permeabilidade, no entanto, deve-se ter cuidados com o solo franco argilo arenoso, com $24 \%$ de argila, e o franco arenoso da camada superficial do Sítio Pilões, pois este têm elevado teor de silte $(24 \%)$, devido a estas condições, pode ocorrer uma maior intensidade da ascensão capilar e rapidez na salinização ou sodificação dos solos da área.

Acrescenta-se que, segundo seus atributos físicos, os solos são propícios à prática da irrigação e, como mencionado anteriormente, deve-se optar por métodos que economizem água, adicionando-se a água próximo à zona radicular das plantas.

Tabela 2. Atributos físicos do solo das áreas estudadas.

\begin{tabular}{|c|c|c|c|c|}
\hline \multirow[t]{2}{*}{ Solos } & \multicolumn{3}{|c|}{ Granulometria } & \multirow[t]{2}{*}{ Classe textural } \\
\hline & \multicolumn{3}{|c|}{----------------- g kg $^{-1}$----------------- } & \\
\hline & Areia & Silte & Argila & \\
\hline $\mathrm{S} 1$ & 582 & 242 & 176 & Franco arenoso \\
\hline $\mathrm{S} 2$ & 662 & 202 & 136 & Franco arenoso \\
\hline SD1 & 520 & 240 & 240 & Franco argilo arenoso \\
\hline SD2 & 640 & 260 & 100 & Franco arenoso \\
\hline $\mathrm{AD}$ & 740 & 140 & 120 & Franco arenoso \\
\hline AND & 844 & 101 & 55 & Areia franca \\
\hline
\end{tabular}

O diagnóstico nas áreas degradadas revelou alta salinidade, subsolo com $\mathrm{CE}=3,6 \mathrm{dSm}^{-1}$; e baixos teores de fósforo $\left(1,6\right.$ e $\left.16 \mathrm{mgdm}^{-3}\right)$, nas áreas desmatadas e subsolos, respectivamente; e matéria orgânica de 3 a $9 \mathrm{gdm}^{-3}$.

\section{Desenvolvimento vegetal}

Comparando-se a altura, número de folhas, MST e relação D/H da mamoneira entre as áreas, independentemente das doses de fósforo aplicadas no solo, foi observado um maior desenvolvimento nas mudas cultivadas no solo de área não degradada (AND), por outro lado, o diâmetro das mudas se desenvolveram mais no solo salino não tratado (SSNT) (Tabela 3).

$\mathrm{O}$ rápido desenvolvimento da parte aérea de mudas são importantes em trabalhos de recuperação de áreas degradadas (FRANCO et al., 1994; NAU \& SEVEGNANI, 1997; FARIA et al., 1997; FARIA et al., 2002), visto que pode cobrir o solo e produzir grande quantidade de folhas, pois, a queda das folhas no solo é importante para a ciclagem de nutrientes e acréscimo da matéria orgânica de baixa relação $\mathrm{C} / \mathrm{N}$, favorecendo as características biológicas, físicas e químicas do solo.

Outro fato que merece destaque é que mudas cultivadas em solos que apresentaram alta salinidade foram levemente superiores em relação aos solos não salinos, dessa forma, a mamoneira não aponta limitações ao seu desenvolvimento dentre os solos testados degradados por sais.

Os melhores resultados nos subsolos degradados não salino é consequência da maior profundidade desses solos e um indicativo de uma homogeneidade da fertilidade do solo ao longo do perfil. Esse fator pode estar relacionado ao tipo de uso do solo e às suas características químicas e físicas (QUEIROZ et al., 2008).

Tabela 3. Massa seca total (MST), Altura, Número de folhas (NF), Diâmetro e Relação Altura/Diâmetro da mamoneira nas áreas (sem aplicação de P).

\begin{tabular}{|c|c|c|c|c|c|}
\hline Solos & $\begin{array}{c}\text { MST } \\
\text { g vaso }^{-1}\end{array}$ & $\begin{array}{l}\text { Altura } \\
\mathrm{cm}\end{array}$ & $\begin{array}{l}\text { NF } \\
\text { un }\end{array}$ & $\begin{array}{l}\text { Diâmetro } \\
\text { mm }\end{array}$ & $\begin{array}{c}\mathrm{H} / \mathrm{D} \\
-\end{array}$ \\
\hline Camada superficial do subsolo não degradado (S1) & $5,8 \mathrm{bc}$ & $34,6 a b$ & $4,0 \mathrm{a}$ & $12,0 \mathrm{~b}$ & $2,8 b$ \\
\hline Camada superficial do subsolo não degradado salino (S2) & $8,0 \mathrm{~b}$ & $39,2 \mathrm{ab}$ & $4,0 \mathrm{a}$ & $13,7 \mathrm{ab}$ & $2,8 b$ \\
\hline Subsolo degradado não salino (SD1) & $4,3 \mathrm{c}$ & $24,0 \mathrm{~b}$ & $4,0 \mathrm{a}$ & $12,0 \mathrm{~b}$ & $2,0 \mathrm{~b}$ \\
\hline Subsolo degradado salino (SD2) & $4,9 b c$ & $31,7 \mathrm{ab}$ & $3,0 \mathrm{a}$ & $13,7 \mathrm{ab}$ & $2,3 b$ \\
\hline Solo da área degradada por desmatamento (AD) & $5,7 \mathrm{bc}$ & $32,3 \mathrm{ab}$ & $4,0 \mathrm{a}$ & $15,3 \mathrm{ab}$ & $2,1 b$ \\
\hline Solo de área não degradada por desmatamento (AND) & $11,7 \mathrm{a}$ & $50,3 \mathrm{a}$ & $4,0 \mathrm{a}$ & $12,0 \mathrm{~b}$ & $4,1 \mathrm{a}$ \\
\hline Subsolo salino não tratado (SSNT) & $6,3 \mathrm{bc}$ & $36,0 \mathrm{ab}$ & $3,0 \mathrm{a}$ & $19,7 \mathrm{a}$ & $1,8 \mathrm{~b}$ \\
\hline
\end{tabular}

* S1 = Camada superficial do subsolo não degradado. S2 = Camada superficial do subsolo não degradado salino. SD1 = Subsolo degradado não salino 1. SD2

$=$ Subsolo degradado salino $2 . \mathrm{AD}=$ Solo de caatinga desmatada. AND = Solo de caatinga não desmatada. ** Nas colunas médias seguidas de mesma letra não diferem entre si pelo teste de Tukey a $5 \%$ de probabilidade.

De acordo com a análise de regressão não houve efeito de regressão para as doses de fósforo aplicadas em todas as variáveis. Os resultados da análise de variância demonstraram não haver diferenças significativas entre os tipos de solos independentemente da aplicação de fósforo nas variáveis, MST, diâmetro, número de folhas e relação altura/diâmetro (Tabela 4). Assim, a espécie em estudo parece ser pouco exigente pela adubação fosfatada em sua fase inicial 
de crescimento. Por outro lado, apenas para a altura, observase um aumento significativo quando adicionado fósforo ao substrato à mamoneira.

Uma possível explicação para o efeito não significativo é de que a reserva de nutrientes encontrados nos solos tenham sido suficientes para o desenvolvimento inicial das mudas, visto que nenhum sintoma visual de deficiência de nutrientes foi observado durante a condução do experimento.
Outros resultados confirmam o baixo potencial de respostas nutricionais de algumas espécies à adição de fósforo nessa fase de crescimento (TUCCI et al. 2011; WALLAU et al. 2008).

De forma geral, os resultados das variáveis de desenvolvimento nas mudas analisadas, em solo com aplicação de fósforo, revelou valores ligeiramente superiores (Tabela 4) sobre as variáveis em relação os mesmos solos sem aplicação de fósforo nos solos (SD1, SD2 e AD).

Tabela 4. Matéria seca total (MST), Altura, diâmetro, Número de folhas e Relação Altura/Diâmetro da mamoneira nas áreas (com aplicação de P).

\begin{tabular}{lccccc}
\multicolumn{1}{c}{ Áreas } & MST & Altura & Diâmetro & N. folhas & H/D \\
un & cm & mm & - \\
\hline Subsolo degradado não salino (SD1) & $5,60 \mathrm{a}$ & $40,42 \mathrm{a}$ & $14,2 \mathrm{a}$ & $4,0 \mathrm{a}$ & $2,8 \mathrm{a}$ \\
Subsolo degradado salino (SD2) & $5,46 \mathrm{a}$ & $28,42 \mathrm{~b}$ & $14,1 \mathrm{a}$ & $3,0 \mathrm{a}$ & $2,0 \mathrm{a}$ \\
Área desmatada (AD) & $4,42 \mathrm{~b}$ & $30,50 \mathrm{~b}$ & $14,2 \mathrm{a}$ & $3,0 \mathrm{a}$ & $2,1 \mathrm{a}$ \\
\hline
\end{tabular}

* SD1 = Subsolo degradado não salino 1. SD2 = Subsolo degradado salino 2. AD = Solo de caatinga desmatada.

** Nas colunas números seguidos de mesma letra não diferem entre si, pelo teste de Tukey a 5\% de probabilidade.

\section{CONCLUSÃO}

Dentre os solos testados o que apresentou maior degradação foi aquele proveniente de solo salino (SD2).

Os subsolos no semiárido apresentam estados de degradação bem diferenciadas, exigindo, quando salinizados, correção com gesso para tornar possível o cultivo do mamona.

As doses de fósforo promoveram ligeiro desenvolvimento nas mudas de mamona, portanto, não se recomenda o uso de fósforo para o cultivo da mamoneira.

\section{REFERÊNCIAS BIBLIOGRÁFICAS}

AGUIAR, A.V.; SILVA, A.M.; MORAES, M. L T.; FREITAS, M. L. M.; BORTOLOZO, F. R. Implantação de espécies nativas para recuperação de áreas degradadas em região de cerrado. In: Simpósio nacional de recuperação de áreas degradadas, 4, 2000, Blumenau. Anais. Blumenau. Sociedade Brasileira de Recuperação de áreas Degradadas, Fundação Universidade Regional de Blumenau, 2000.

ALVES, M. C. \& SUZUKI, L. E. A. S. Influência de diferentes sistemas de manejo do solo na recuperação de suas propriedades físicas. Acta Sci. Agron., 26:27-34, 2004 .

BEZERRA, R. M. R. Crescimento Inicial de Espécies Arbóreas Nativas em Solos De Áreas Degradadas da Caatinga Em Condição de Viveiro 2012. 39 p. Monografia (Graduação em Engenharia Florestal) Universidade Federal de Campina Grande, Centro de Saúde e Tecnologia Rural, Patos - PB, 2012.

CFSEMG - Comissão de Fertilidade do Solo do Estado de Minas Gerais. Recomendações para uso de corretivos e fertilizantes em Minas Gerais: $5^{\text {a }}$ aproximação. Viçosa 1999. 360p.

CHAER, G. M., RESENDE, A. S. DE, CAMPELLO, E. F. C., FARIA, S. M. DE, BODDEY, R. M. Nitrogenfixing legume tree species for the reclamation of severely degraded lands in Brazil. Oxford: Oxford University Press, 2011. Tree Physiology 31, p.139-149.

CHAUHAN, R.P.S.; CHAUHAN, C. P. S. A modification to Shoonover's method of gypson requirement determination of soil. Australian Journal of Soil Research, v. 17, p.367-370. 1979.

EMATER-PB. Sugestões de adubação para o estado da paraíba - $1^{a}$ proximação. João Pessoa-PB. 1979. 105p.

EMBRAPA. Centro Nacional de Pesquisa de Solos. (Rio de Janeiro, RJ). Manual de métodos de análises de solo. 2 ed. rev. atual. Rio de Janeiro: EMBRAPA/CNPS, 1997. 212 p. (EMBRAPA/CNPS. Documentos,1).

FARIA, J. M. R.; DAVIDE, A. C.; BOTELHO, S. A. Comportamento de espécies florestais em área degradada, com duas adubações de plantio. Cerne, Lavras, MG, v.3, n.1, p.25-44, 1997.

FARIA, S. M. DE.; SILVA, M. G.; GRAIG, J.; DIAS, S. J.; LIMA, H. C.; NARA, M. Revegetação com espécies arbóreas fixadoras de nitrogênio em taludes de exploração de ferro na Samarco Minerações Mariana, MG. In: SIMPÓSIO NACIONAL SOBRE RECUPERAÇÃO DE ÁREAS DEGRADADAS "ÁGUA E BIODIVERSIDADE", 5, 2002, Belo Horizonte, MG. Anais... Belo Horizonte: SOBRADE, 2002. p.521-522.

FERREIRA, D. F.; Sisvar. Versão 5.3 (Build 77). DEX/UFLA. 2010.

FRANCO, A. A.; CAMPELLO, E. F.; DIAS, L. E.; FARIA, S. M. de. Revegetação de áreas de mineração em Porto Trombetas - PA com leguminosas arbóreas noduladas e micorrizadas. In: Simpósio Sul-Americano e II Simpósio Nacional Sobre Recuperação de Áreas Degradadas, 1, 1994, Foz do Iguaçu, PR. Anais... Curitiba: FUPEF, 1994. p. $145-153$. 
NASCIMENTO, J. T..; SILVA, I. F.; SANTIAGO, R.D.; \& SILVA E NETO, L. F. Efeito de leguminosas nas características químicas e matéria orgânica de um solo degradado. Revista. Brasileira. de Engenharia. Agrícola e Ambiental, 7:457-462, 2003.

NAU, S. R.; SEVEGNANI, L. Vegetação recolonizadora em mina de argila e propostas para recuperação ambiental. In: Simpósio Nacional Sobre Recuperação de Áreas Degradadas, 3, 1997, Ouro Preto, MG, Anais... Ouro Preto: SOBRADE-SIF, 1997. p.54-66.

OLIVEIRA, M.K.T.; OLIVEIRA, F.A.; MEDEIROS, J.F.; LIMA, C.J.G.S.; GUIMARÃES, I.P. Efeito de diferentes teores de esterco bovino e níveis de salinidade no crescimento inicial da mamoneira (Ricinus communis L.). Revista Verde v.1, n.1, p. 47-53, 2006.

QUEIROZ, D. S.; SALGADO, L. T.; FERNANDES, L.O. Recuperação de pastagens degradadas. Informe Agropecuário, v.29, n.244, p.55-65, 2008.

SCHIAVO, J.A. Revegetação de áreas degradadas pela extração de argila, com espécies micorrizadas de Acacia mangium, Sesbania virgata e Eucalyptus camaldulensis. Campos dos Goytacazes- RJ, Universidade Estadual do Norte Fluminense Darcy Ribeiro - UENF. 117p. 2005. (Tese - Doutorado em Produção Vegetal).

TOMÉ Jr., J. B. Manual para Interpretação de Análise de Solo. Livraria e Editora Agropecuária, Guaíba, RS, 1997. $247 \mathrm{p}$

TUCCI, C. A. F.; SANTOS, J. Z. L.; JUNIOR, C. H. S.; SOUZA, P. A.; BATISTA, I. M. P.; VENTURIN, N. Desenvolvimento de mudas de Swietenia macrophylla em resposta a nitrogênio, fósforo e potássio. Floresta, Curitiba, PR, v. 41, n. 3, p. 471-490, jul./set. 2011.

UNIVERSIDADE FEDERAL DO CEARÁ. Recomendações de adubação e calagem para o estado do Ceará. 1993. 248 p.

WALLAU, R. L. R. DE; BORGES, A. R.; ALMEIDA, D. R. DE; CAMARGOS, S. L. Sintomas de deficiências nutricionais em mudas de mogno cultivadas em solução nutritiva. Cerne, Lavras, v. 14, n. 4, p. 304 - 310, 2008. 